Southern Illinois University Edwardsville

SPARK

SIUE Faculty Research, Scholarship, and Creative Activity

2021

\title{
From Stress to Success: Leveraging the Online Experience for Information Systems Students
}

Connie Barber

Southern Illinois University Edwardsville, cobarbe@siue.edu

Follow this and additional works at: https://spark.siue.edu/siue_fac

\section{Recommended Citation}

Barber, Connie, "From Stress to Success: Leveraging the Online Experience for Information Systems Students" (2021). SIUE Faculty Research, Scholarship, and Creative Activity. 109.

https://spark.siue.edu/siue_fac/109

This Article is brought to you for free and open access by SPARK. It has been accepted for inclusion in SIUE Faculty Research, Scholarship, and Creative Activity by an authorized administrator of SPARK. For more information, please contact magrase@siue.edu. 


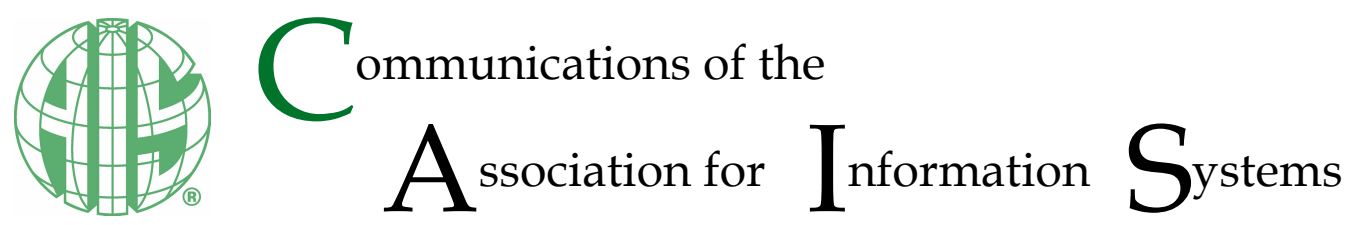

\title{
Accepted Manuscript
}

\section{From Stress to Success: Leveraging the Online Experience for Information Systems Students}

\author{
Connie S. Barber \\ Computer Management \& Information Systems \\ Southern Illinois University Edwardsville \\ cobarbe@siue.edu
}

Please cite this article as: Barber, Connie: From Stress to Success: Leveraging the Online Experience for Information Systems Students, Communications of the Association for Information Systems (forthcoming), In Press.

This is a PDF file of an unedited manuscript that has been accepted for publication in the Communications of the Association for Information Systems. We are providing this early version of the manuscript to allow for expedited dissemination to interested readers. The manuscript will undergo copyediting, typesetting, and review of the resulting proof before it is published in its final form. Please note that during the production process errors may be discovered, which could affect the content. All legal disclaimers that apply to the Communications of the Association for Information Systems pertain. For a definitive version of this work, please check for its appearance online at http://aisel.aisnet.org/cais/. 


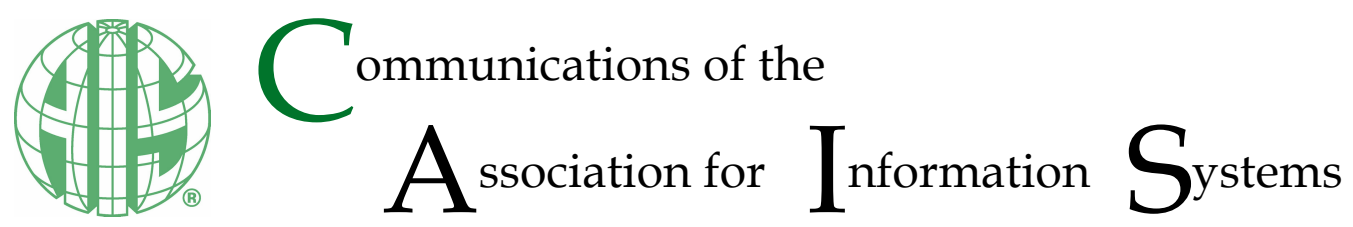

\title{
From Stress to Success: Leveraging the Online Experience for Information Systems Students
}

\author{
Connie S. Barber \\ Computer Management \& Information Systems \\ Southern Illinois University Edwardsville \\ cobarbe@siue.edu
}

\begin{abstract}
:
The development of the coronavirus and universities' unprecedented and abrupt transition to remote learning were disruptions to higher education that impacted stress levels for both graduate and undergraduate students. However, remote learning could be implemented in a method with lower stress that also helps prepare students for an increasingly digital workplace. Additionally, different modes of remote learning could enable students to enhance their digital competencies. In this paper I describe a teaching practice in which I modified one undergraduate and one graduate course to reduce the stress of remote learning and provide opportunities for students to enhance their digital competencies of adaptability, conceptual thinking, and digital literacy. Overall, the students and I found the experience to be positive. I will continue this practice in online courses even once the mode of delivery for higher education campuses returns to face-to-face.
\end{abstract}

Keywords: Digital workforce, Digital competencies, Communication skills, Remote learning

[Department statements, if appropriate, will be added by the editors. Teaching cases and panel reports will have a statement, which is also added by the editors.]

[Note: this page has no footnotes.]

This manuscript underwent [editorial/peer] review. It was received $x x / x x / 20 x x$ and was with the authors for $X X$ months for $X X$ revisions. [firstname lastname] served as Associate Editor.] or The Associate Editor chose to remain anonymous.] 


\section{Introduction}

In March of 2020 the learning experiences of thousands of information systems students were turned upside down when universities across the United States declared that the remainder of the semester would be taught remotely. Suddenly students were struggling to learn content such as programming languages, database design, and networking methods without the advantages of face-to-face instruction. Additionally, instructors were frantically trying to adapt learning materials to the online environment and develop some level of meaningful learning experiences for their students. Students and instructors worked to stay motivated and engaged in activities of learning. Stress levels for students and instructors were fueled by a pandemic that left some students without jobs, housing, and in some cases, loved ones. We know that productivity requires skills "to cope effectively with stressors," (Earnest \& Dwyer, 2010, p. 3). But who was equipped with skills to cope during an event of such magnitude?

It's no surprise that college students face challenges and perceive significant stress when seeking their degrees. Female graduate students have been found to experience stress regarding "changing work responsibilities, beginning/ceasing formal education, financial difficulties, and illness/injury to family member" (Arric, Young, Harris, \& Farrow, 2011, p. 149). For some, the pandemic caused multiple of those stressors to occur at the same time. Additionally, non-traditional students have been found to be "more likely to be at risk for psychological distress than their traditional counterparts" (Hardin, 2008, p. 53) and a pandemic could impact those already experienced stressors. First generation college (FGC) students struggle with high levels of stress around finances, social isolation, and insufficient academic preparedness (Garriott \& Nisle, 2018; Mehta, Newbold, \& O'Rourke, 2011), Additionally, these stressors and how first generation college students manage them impact their retention (Mehta et al., 2011; Pratt, Harwood, Cavazos, \& Ditzfeld, 2019). Traditional university students also experience psychological distress and factors such as "life satisfaction, self-esteem, optimism, and self-efficacy" (Saleh, Camart, \& Romo, 2017, p. 1) can also increase stress.

In addition to the first generation student stressors, those FGCs who hold minority status may also experience stress associated with discrimination or cultural differences (Phinney \& Haas, 2003). Also, students who are caught in the digital divide face the added challenges of gaining access to technology and being able to use the required technology (Journell, 2007). When the aspects of race, ethnicity, LGBTQ+, and international student status were added to the previously mentioned factors, the situation for students became a tangle of emotions and stress. Then they were required to remotely complete academic work and take exams.

In this practice paper I share an experience of modified student assessment and testing that leverages the tools of the online environment to the students' advantage. I include a description of the problem in the next section, followed by an explanation of the practice. I then describe my experiences and lessons learned.

\section{Problem}

The swift move to remote instruction due to the coronavirus prompted an increased concern for academic integrity in the online learning environment. I was required to shift one undergraduate (UG) and one graduate (GR) systems analysis and design course to full online delivery. The undergraduate course was a flipped structure and the graduate course was hybrid - both originally with face-to-face hours. Typically, during both classes, we engaged in a lot of hands-on practice in the classroom. The shift to remote learning meant that I then had to deal with issues like:

- How do I create those hands-on experiences in an online environment?

- How do I move students beyond memorization of content to application of concepts in the online environment?

- How can I be certain that the person completing the work or taking the exam is the student?

- If I use an online proctoring service how do I manage exams for students who feel that having a stranger watch them online and see where they live is a violation of their privacy?

The experiences and struggles of that spring semester prompted me to rethink my strategies for my online summer courses. I revised the assignments and exams for two courses: an elective titled Visual Basic for Access Applications (UG), and another Software Systems Design course (GR). The practice was simple in 
execution from my perspective and included two basic steps for students: (1) do the work and, (2) explain the work. Table 1 provides more detail about the work of the students and instructor for each course.

Table 1. Practice Details for Students and Instructors

\begin{tabular}{|c|c|c|c|c|}
\hline Practice Details & Student & Instructor & UG Course & GR Course \\
\hline $\begin{array}{l}\text { Edit assignment/exam } \\
\text { instructions }\end{array}$ & & $\sqrt{ }$ & \multicolumn{2}{|c|}{$\begin{array}{l}\text { Be specific. Section1: document/prototype completion } \\
\text { tasks. Section 2: video completion tasks. }\end{array}$} \\
\hline Create rubrics in the LMS & & $\sqrt{ }$ & \multicolumn{2}{|c|}{$\begin{array}{l}\text { Be specific. Align with Sections } 1 \text { and } 2 \text { of instructions } \\
\text { Provide to students prior to submission and grading }\end{array}$} \\
\hline Create an explanation video & & $\sqrt{ }$ & \multicolumn{2}{|c|}{$\begin{array}{l}\text { Explain how the students will be completing the } \\
\text { assignments/exams, AND why this is the format. } \\
\text { Connect their tasks/outcomes with opportunities. }\end{array}$} \\
\hline $\begin{array}{l}\text { Complete the } \\
\text { assignment/exam }\end{array}$ & $\sqrt{ }$ & & $\begin{array}{l}\text { Develop the Access } \\
\text { database including the } \\
\text { specific requirements. }\end{array}$ & $\begin{array}{l}\text { Develop the planning, } \\
\text { analysis, design } \\
\text { documents according to } \\
\text { the requirements. }\end{array}$ \\
\hline $\begin{array}{l}\text { Record themselves using } \\
\text { Zoom }\end{array}$ & $\sqrt{ }$ & & $\begin{array}{c}\text { Demonstrate the } \\
\text { functionalities of the Access } \\
\text { database and explain how it } \\
\text { addresses business } \\
\text { requirements. }\end{array}$ & $\begin{array}{l}\text { Display planning, } \\
\text { analysis, and/or design } \\
\text { documents and explain } \\
\text { how they represent the } \\
\text { business processes. }\end{array}$ \\
\hline $\begin{array}{l}\text { Upload recording to TechSmith } \\
\text { Knowmia }\end{array}$ & $\sqrt{ }$ & & $\begin{array}{l}\text { Each assignment/exam } \\
\text { must have a separate video. }\end{array}$ & $\begin{array}{c}\text { Each exam must have a } \\
\text { separate video. }\end{array}$ \\
\hline $\begin{array}{l}\text { Submit the 'share' link from } \\
\text { TechSmith Knowmia in LMS }\end{array}$ & $\sqrt{ }$ & & \multicolumn{2}{|c|}{$\begin{array}{c}\text { Copy the share link for each individual video and paste } \\
\text { it into the text submission section for each } \\
\text { assignment/exam. }\end{array}$} \\
\hline $\begin{array}{l}\text { Grade the } \\
\text { documents/prototype }\end{array}$ & & $\sqrt{ }$ & \multicolumn{2}{|c|}{ Provide detailed feedback for improvement. } \\
\hline $\begin{array}{l}\text { Grade the verbal } \\
\text { communication/networking } \\
\text { skills }\end{array}$ & & $\sqrt{ }$ & \multicolumn{2}{|c|}{$\begin{array}{c}\text { Provide specific feedback on how students can } \\
\text { improve these skills toward obtaining a job/internship } \\
\text { and/or on the current job. }\end{array}$} \\
\hline
\end{tabular}

Students in the undergraduate courses developed a database for the campus police to support the business process of tracking employee training. Students in the graduate course developed system design documents such as a scope statement, work breakdown structure, ERD, DFD, etc. for the planning, analysis, and design stages of the SDLC. Their business scenario was a hypothetical school for magically gifted youth that was in need of an information system to track residents and accounts as well as courses and registration. To complete the assignments and exams students used software that was already free for them through the university such as Word, Zoom for recording their video, and TechSmith Knowmia for hosting the video. In the graduate course students also used draw.io and/or Microsoft Visio to complete the exam. It is important to note that in the undergraduate course all assignments and exams were completed through the described practice. In the graduate course, only the final exam was administered in this manner.

\section{Experiences}

I had two basic expectations: that students will complete their own documents/prototype, and that they will be able to demonstrate/discuss how the documents/prototype are aligned with the business process. In the 
undergraduate course, the engagement of students was quite varied. One student completed a 5-minute video for a 100-point exam. A different student recorded a 1.5-hour video for a 50-point assignment. Some students used the instructions for the video as a checklist to ensure that they covered all required elements in the video. If they couldn't get an element of the database to work, they discussed it in the video. Others winged it and just demonstrated what they knew worked in their database and didn't go into further discussion about their experience. The choice to elaborate could be caused by lack of confidence in either their technical skills or their presentation skills. However, from my point of view, watching them actually navigate the through their database provided the opportunity to understand how they were using the software and provide more targeted feedback regarding both the use of Microsoft Access and development within it. Regarding their verbal communication and networking skills, hearing how they discussed the database and their method for demonstration provided the opportunity to guide them in using professional language, having a plan for presenting, and making the connections between their work and the business processes being improved/enhanced.

I surveyed the students following the course. Unfortunately, only two of the six students responded. One student noted "I preferred her video method as opposed to ProctorU for the exams." The responses when asked about the level of stress created by the assignments and exams are noted in Table 2. One student felt the video assignments and exams created a lot of stress. The other indicated that it was more stressful for exams than for assignments. The respondents indicated that they had not taken any online classes prior to my class. As such, they could not compare my method to prior online courses. Both respondents were female and were in the 18-24 age range. Both identified as traditional students. One indicated they are both a working student and a commuter.

Table 2. Stress Experienced by Undergraduates

\begin{tabular}{|r|r|r|}
\hline Amount of Stress & Assignments & Exams \\
\hline A great deal & 0 & 0 \\
\hline A lot & 1 & 1 \\
\hline A moderate amount & 0 & 1 \\
\hline A little & 1 & 0 \\
\hline None at all & 0 & 0 \\
\hline
\end{tabular}

Additional information can be extracted from my student evaluations for the course. Three out of six students completed the student evaluations for the course. I was scored a $5 / 5$ on all evaluation statements by all three students, including the statement "[t]he instructor used teaching strategies that enhanced my understanding of course content".

Students in the graduate course were more amenable to completing the survey with six out of eight responding. The respondent genders were 3 females and 3 males. Their age ranges and student type are shown in Table 3. The majority of respondents were in the 25-34 age range. Regarding student type, I allowed respondents to select all that applied. While the majority identified as traditional students, there was also diversity in the class as identified by the selections in the international, disabilities, and working student groups.

Table 3. Demographics of Graduate Students

\begin{tabular}{|c|c|c|c|}
\hline Age Range & Count & Student Type & Count \\
\hline $18-24$ & 1 & Traditional Student & 4 \\
\hline $25-34$ & 4 & Non-traditional Student & 2 \\
\hline $45-54$ & \multirow[t]{3}{*}{1} & International Student & 3 \\
\hline & & Student with Disabilities & 1 \\
\hline & & Working Student & 2 \\
\hline
\end{tabular}

Regarding the amount of stress students experienced with the course, Table 4 shows the comparison of stress students believed is induced by each testing method. For both the proctoring services and lockdown browser there was one respondent who had not used them. Student comments regarding proctoring 
services included "the worst service I have used in my entire life", "[o]nline proctoring services are very stressful and I feel are often not accommodating to what is going on in one's home", and "I feel like being watched by a proctor in real time adds additional stress that distracts from my ability to focus completely on the exam".

Table 4. Testing Mechanism Stress for Graduate Students

\begin{tabular}{|r|r|r|r|}
\hline Amount of Stress & $\begin{array}{l}\text { Proctoring } \\
\text { Service }\end{array}$ & $\begin{array}{l}\text { Lockdown } \\
\text { Browser }\end{array}$ & $\begin{array}{l}\text { Video } \\
\text { Exam }\end{array}$ \\
\hline A great deal & 1 & 0 & 0 \\
\hline A lot & 2 & 0 & 0 \\
\hline A moderate amount & 0 & 1 & 0 \\
\hline A little & 1 & 2 & 3 \\
\hline None at all & 1 & 2 & 3 \\
\hline
\end{tabular}

The lockdown browser was viewed as less stressful than the proctoring service. Comments included, "[t]his is less stressful than online proctor services and doesn't really bother me" and "[i]t was less cumbersome, but still added extra work to the process. But again, seemed necessary". In general, students understood the need to ensure academic integrity. Overall, though, the video exam was not only less stressful than the proctoring service and lockdown browser, but students identified benefits of the method. Comments from students were encouraging:

- Often, when approaching traditional exams, one is somewhat forced to memorize and regurgitate. I felt that I had the opportunity to really apply concepts and explain my reasoning rather than just going through the multiple choice motions.

- I thought it worked really well. It made us actually go back through and evaluate everything we did during the course. I think that especially in grad school classes, it makes no sense to have normal exams. Regurgitating information is of no use to us.

- I think that the method of reviewing assignments in a presentation and explaining how they relate to each other gave me a better understanding of the course material and provided a review of information that was taught in the beginning of the course.

- I enjoyed the exam for CMIS 570 very much! It was both a welcome change from the standard online process, and was also a very good way to collect and summarize all of the work we had done for the class throughout the term.

When I administered the final exam for the graduate course, I opened the exam instructions on Monday at noon. Students had until Wednesday at midnight to revise their documents based on feedback received throughout the course and create their video. I did not tell them the exam structure prior to their accessing the exam instructions on Monday. A few students commented about this:

- I was a bit surprised by the video final but I really liked it.

- My only complaint is that I wish there was an example to observe before completing my own to better understand what was wanted.

- A little preparation going in to the term would have been beneficial, but I understand this was a new idea.

As students in the graduate course noted, the structure of the exam allowed them to synthesize the material they had learned across the seven weeks of the course. This works well for the concepts taught in systems analysis and design because the final deliverable is a consolidation of the design documents created throughout the course. For the undergraduate database course, the final deliverable was a functional database. Therefore, having students discuss how their final deliverable aligns with the business processes and meets the business need/solves the business problem is a logical ending to both courses. The variability in chosen system design provides a natural mechanism for each student's result to be original. This technique may not be as effective in courses where students do spend the majority of time memorizing content. Additionally, both of the courses in which I implemented this practice had fewer than eight students. However, the time I spent grading the videos was approximately the same amount of time I would spend 
grading traditional assignments and exams. Setting up and managing the assignments and exams took the same amount of time as traditional assignments and exams.

\section{Lessons Learned}

I learned three big lessons from the abrupt shift to remote learning in the spring:

- Learning: even in a pandemic, students have a thirst for knowledge. The majority of students in the courses that I shifted to remote learning worked really hard to stay motivated and engaged. Undergraduate students reached out to me frequently via email. Graduate students frequently attended my Zoom office hours. Providing unique experiences for them in the online environment helps motivate them to stay engaged.

- Technology: the more control we give to technology the more problems can arise. Lockdown browsers integrated with learning management systems (LMS) can glitch during exams. Proctoring service systems can kick students from exams.

- Privacy: although students live in a fast-paced, social media saturated world, they are still concerned with their privacy. More than one student expressed feeling violated by online proctoring services that require they scan their setting for a stranger to see and to show an ID that may have location identifying information.

I attempted to address these lessons through the implementation of the video assignments and exams. As noted in the results, the graduate students indicated that additional learning did take place through the video final exam. The technology issues were mitigated by allowing the students to develop their documents and video outside of the LMS and simply upload the final document inclusive of a viewing link for the video. Also, because the video assignments and exams were hosted in TechSmith Knowmia and students only provided a link through Blackboard, there were no privacy concerns for the students. But my practice also held its own lessons:

Video instruction: students need to be provided with a minimum amount of time expectation for a given assignment/exam presentation. To aid students in meeting that requirement, instructors should provide them will additional discussion ideas if they find themselves struggling. For example, with the database project students would have benefited from discussing what went wrong, what they tried, and even demonstrating how they tried to complete the steps.

Preparing for recording: students need to be encouraged to practice before they record a video. This practice needs to include not just making sure the database works, but also what they will discuss for each video content requirement. This is similar to the instruction given to students when they present in a faceto-face setting.

Overall, I had a positive experience with this practice. It relieves the stress of the online proctoring service and lockdown browser while providing the students with an opportunity to synthesize the material they studied in the course and articulate their knowledge and understanding. Additionally, I get more of a sense of their content absorption.

\section{Conclusion}

When we consider the likelihood that graduates will find jobs remotely or current students may find remote internships, it is important to acknowledge that an increasingly digital workforce requires digital skills. Competencies for the digital workforce include adaptability, conceptual thinking, and digital literacy. Being adaptable displays flexibility when situations change. Conceptual thinking includes the application of models and frameworks to new situations. Digital literacy is the "skill at using a variety of technologies to collect, synthesize and apply knowledge" (Petter, Barber, Barber, \& Berkley, 2018, p. 317). Through the practice presented in the Section 4, I demonstrate how assignments and exams can be modified to enhance student competencies of adaptability, conceptual thinking, and digital literacy, turning the stress of remote learning into success in the digital workforce.

While I have little ability to relieve the stressors that students are facing outside of the classroom, I can create a remote environment where they can improve their digital literacy with low stakes. Through the use of Zoom and TechSmith Knowmia students have the opportunity to enhance their digital competency of adaptability. Their conceptual thinking competency can be built through the recorded discussions of their knowledge of the course material. Additionally, the successful execution of all the required software can 
both develop their digital literacy and the skills necessary to prepare them for the digital workforce (Petter, et al., 2018). Also, by using software that is free to students I remove one barrier to technology access experienced through the digital divide (Journell, 2007). Students could essentially use a smartphone to make a Zoom recording, upload it to TechSmith Knowmia, and then provide the link via the LMS.

The pandemic has caused many changes in higher education. Not getting to spend time with students in a face-to-face setting has been difficult for many instructors. Pedagogically, not all course content lends itself well to being transitioned to an online learning environment. However, getting the chance to see and hear students through the practice presented in this paper has bolstered my resolve to continue developing mechanisms to leverage the online experience for students and help them transform stress into digital workforce success.

\section{References}


Arric, L., Young, K., Harris, S., \& Farrow, V. (2011). An Analysis of Stress Levels of Female Graduate Students in An Online Program. Advancing Women in Leadership, 31(31), 144-152.

Earnest, D. R., \& Dwyer, W. O. (2010). In Their Own Words: An Online Strategy for Increasing StressCoping Skills Among College Freshman. College Student Journal, 44(4), 888-900.

Garriott, P. O., \& Nisle, S. (2018). Stress, Coping, and Perceived Academic Goal Progress in FirstGeneration College Students: The Role of Institutional Spports. Journal of Diversity in Higher Education, 11(4), 436-450. https://doi.org/10.1037/dhe0000068

Hardin, C. J. (2008). Adult Students in Higher Education: A Portrait of Transitions. New Directions for Higher Education, (144), 49-57. https://doi.org/10.1002/he

Journell, W. (2007). The Inequities of the Digital Divide: Is e-learning a solution? E-Learning and Digital Media, 4(2), 138-149. https://doi.org/10.2304/elea.2007.4.2.138

Mehta, S. S., Newbold, J. J., \& O'Rourke, M. A. (2011). WHY DO FIRST-GENERATION STUDENTS. College Student Journal, March(1), 1-18.

Petter, S., Barber, C., Barber, D., \& Berkley, R. (2018). Using Online Gaming Experience to Expand the Digital Workforce Talent Pool. MIS Quarterly Executive, 17(4), 315-332. https://doi.org/10.17705/2msqe.00004

Phinney, J. S., \& Haas, K. (2003). The Process of Coping Among Ethnic Minority First-Generation College Freshman: A Narrative Approach. Journal of Social Psychology.

Pratt, I. S., Harwood, H. B., Cavazos, J. T., \& Ditzfeld, C. P. (2019). Should I Stay or Should I Go? Retention in First-Generation College Students. Journal of College Student Retention: Research, Theory and Practice, 21(1), 105-118. https://doi.org/10.1177/1521025117690868 


\section{About the Author}

Connie S. Barber is an Assistant Professor of Information Systems at Southern Illinois University Edwardsville. Her research addresses gamification in IS education, the use of massively multiplayer online role-playing games to study virtual teams and organizations, and the unintended consequences of social media. Her work is published in the European Journal of Information Systems, MISQ Executive, Information \& Management, Academy of Management Learning and Education, and the International Journal of Virtual Communities and Social Networking.

Copyright ( 2020 by the Association for Information Systems. Permission to make digital or hard copies of all or part of this work for personal or classroom use is granted without fee provided that copies are not made or distributed for profit or commercial advantage and that copies bear this notice and full citation on the first page. Copyright for components of this work owned by others than the Association for Information Systems must be honored. Abstracting with credit is permitted. To copy otherwise, to republish, to post on servers, or to redistribute to lists requires prior specific permission and/or fee. Request permission to publish from: AIS Administrative Office, P.O. Box 2712 Atlanta, GA, 30301-2712 Attn: Reprints or via e-mail from publications@aisnet.org. 